\title{
Vitamin A supplementation among children in India: Does their socioeconomic status and the economic and social development status of their state of residence make a difference?
}

Sutapa Agrawal, Praween K. Agrawal'

Epidemiologist, South Asia Network for Chronic Disease, Public Health Foundation of India,

C-1/52, First Floor, Safdurjung

Development Area, ${ }^{1}$ Senior

Programme Officer, Population Council, 42, Golf Links, First Floor, New Delhi, India

Address for the Correspondence:

Dr. Sutapa Agrawal, Epidemiologist, South Asia Network for Chronic Disease, Public Health Foundation of India, C-1/52, First Floor,

Safdurjung Development Area, New Delhi - 110 016, India. E-mail: sutapaiips@rediffmail.com, sutapa.agrawal@phfi.org

\begin{tabular}{|l|}
\hline Access this article online \\
\hline Website: www.ijmedph.org \\
\hline DOI: $10.4103 / 2230-8598.109322$ \\
\hline Quick response code: \\
\hline
\end{tabular}

Background: India has the largest percentage/number of vitamin A deficient children in the world. However, the effectiveness of a program of vitamin A supplementation at the population level has been rarely examined. We aim to examine the status of vitamin A supplementation among preschool children in India and its association with their socioeconomic and demographic characteristics and the social and economic development level of the State in which they reside. Materials and Methods: Data are from a cross-sectional study of 20,802 children aged 12-35 months whose mothers participated in the National Family Health Survey 3 (NFHS-3) conducted during 2005-2006. The association between the socioeconomic and demographic characteristics of the children, the social and economic development status of the State in which they reside and vitamin A supplementation status was examined by means of unadjusted and adjusted logistic regression models. Results: Only $25 \%$ of the children in India received vitamin A supplementation, indicating a poor coverage, and the differences between the States were wide $(<10 \%$ to $>45 \%)$. Rural children (OR: $1.20 ; 95 \% \mathrm{Cl}: 1.10-1.30 ; P<0.0001$ ) and children of educated mothers (OR: $2.40 ; 95 \% \mathrm{Cl}: 2.04-2.83 ; P<0.0001)$ were more likely to receive vitamin A supplementation than others. Children born in a higher birth order (6+) (OR: $0.54 ; 95 \% \mathrm{Cl}: 0.46-0.63 ; P<0.0001)$ and those residing in states with low levels of social and economic development (OR: 0.51; 95\% Cl: 0.46-0.57; $P<0.0001$ ) were only about half as likely to receive vitamin $A$ supplementation as their counterparts. Conclusion: The national vitamin A supplementation program in India did not reach a majority of preschool children in 2005. Greater maternal formal education, higher household wealth status and high social development status of their State of residence appears to be an important determinant for receipt of a vitamin A supplementation by preschool children in India.

Key words: Children aged 12-35 months, India, logistic regression, NFHS-3, State's social and economic status, vitamin A supplementation

\section{INTRODUCTION}

Vitamin A deficiency (VAD) is a major public health problem in many developing countries, including India. India has the largest percentage as well as the largest absolute number of vitamin A-deficient children in the world. The Lancet child survival series ${ }^{[1,2]}$ lists vitamin A supplementation among the key interventions achievable at a large scale that have proven potential to reduce the number of preventable child deaths each year. ${ }^{[3]}$ Moreover, vitamin A supplementation is recognized as one of the most cost-effective interventions for improving child survival. ${ }^{[4,5]}$ Thus, vitamin A programming is a prerequisite for achieving one of the Millennium Development Goals (MDG 4), particularly in countries with high under-five mortality and/or VAD rates.

The Lancet child survival series ${ }^{[1,2]}$ estimated that making vitamin A supplementation universal in reach can contribute $2 \%$ to the expected two-thirds reduction in child deaths that would occur if all currently known effective interventions were simultaneously taken to near-universal coverage. By using certain indicators, the communities or populations where VAD is a public health concern have been identified. Traditionally, the means of identification have been clinical signs and symptoms of 
Xerophthalmia, sometimes supported by evidence of deficient blood values and deficient dietary intakes of the vitamin, but these means have their limitations. Of late, the prevalence of maternal night blindness has been postulated as a useful and reliable indicator of the vitamin A status of the community. ${ }^{[6]}$

\section{Global burden of vitamin A deficiency}

An estimated 4 million children under the age of 5 years are affected by xerophthalmia, a serious eye disorder that can be caused by moderate to severe deficiency and can lead to blindness. ${ }^{[7]}$ Far greater numbers of children show no external signs of VAD but live with dangerously low vitamin A stores, leaving them vulnerable to infection and with reduced immunity to fight common childhood diseases. Because of technical and financial constraints, such as the limited ability to transport and store biological samples, or lack of laboratory facilities, many countries have not been able to assess the true level of deficiency. It is estimated that 127 million preschool children may be affected globally, ${ }^{[7]}$ and most of this burden is concentrated in South Asia and sub-Saharan Africa.

A 2003 article in The Lancet, "Where and why are 10 million children dying every year?" revealed that $90 \%$ of preventable child deaths occur each year in a limited number of countries. ${ }^{[1]}$ Significant global progress toward MDG 4 could be achieved by reaching young children in these countries with a package of well-established child survival interventions, including vitamin A supplementation.

As seen, VAD is a major contributor to the mortality of children under 5 years of age, ${ }^{[8]}$ and improving the vitamin A status of deficient children through supplementation enhances their resistance to disease and can reduce mortality from all causes by approximately $23 \% .{ }^{[9]}$ Guaranteeing high supplementation coverage is therefore critical, not only for counteracting the vitamin deficiency but also as a central element of the child survival agenda. Delivery of high-dose supplements remains the principal strategy for controlling VAD. Food-based approaches, such as food fortification and consumption of foods rich in vitamin $\mathrm{A}$, are becoming increasingly feasible but have not yet attained coverage levels similar to supplementation in most affected areas.

\section{Vitamin A supplementation status in India}

India has long recognized VAD as the leading cause of preventable blindness in children, and was the first country to start using large-dose vitamin A supplementation at scale, starting with selected states in 1970. Under this program, which is sponsored by the Ministry of Health and Family Welfare, Government of India, children between 9 months and 3 years are given six-monthly doses of vitamin A. Some states in India have decided to extend that period to cover children until they reach 5 years of age, as recommended by the World Health Organization (WHO). The administration of the first two doses is linked with routine immunization. Although the supplementation program was started as a short-term measure to prevent blindness in children, it has been going on for the last three decades, and its continuation has become a subject of national debate. ${ }^{[10]}$

Presently in India, vitamin A supplementation is done through the existing network of primary health centers and subcenters. The female multipurpose worker and other paramedics of the health centers are responsible for administering vitamin A concentrates to children in the 9-35-months age group. The services of the Integrated Child Development Scheme (ICDS) functionaries are also utilized for the implementation of the program. ${ }^{[1]}$ Vitamin A is supplied in Drug Kit A to subcenters. Each kit, supplied every 6 months, contains six bottles of $100 \mathrm{ml}$, i.e., $1200 \mathrm{ml}$ per year. The supplies are adequate to cover all the eligible children who are under the jurisdiction of the subcenters. Although the supplementation program was initially started in India, it now lags behind several African and even the neighboring countries in terms of implementation, and coverage is quite low, reaching only $25 \%$ of the children aged $12-35$ months. ${ }^{[12]}$

In view of the above, the aim of this study is to examine the status of vitamin A supplementation among preschool children in India and its association with the socioeconomic characteristics of the mothers and the social and economic development status of their State of residence.

\section{MATERIALS AND METHODS}

\section{Data}

Data were mainly retrieved from India's National Family Health Survey 3 (NFHS-3), conducted during 2005-2006. ${ }^{[12]}$ NFHS-3 is a nationally representative survey that includes a household sample, covering everyone in the sampled households, and an individual sample, covering all ever-married women aged 15-49 years within those households. The NFHS-3 collected demographic, socioeconomic and health information from a nationally representative probability sample of 124,385 ever-married women aged 15-49 years and 74,369 men aged 15-54 years residing in 109,041 households in India. All the states of India are represented in the sample (except the small Union Territories), covering more than $99 \%$ of the country's population. The sample is a multistage cluster random sample with an overall response rate of $98 \%$. Details of sample design, including sampling framework, are provided in the basic survey report for all India. ${ }^{[12]}$ In this study, 20,802 children in the age group of 12-35 months have been considered for the vitamin A supplementation analysis.

\section{Response variable}

The NFHS-3 collected information on the administration of vitamin A supplements for the youngest child aged 6-35 months living with the mother in the selected household. The response variable is a dichotomous variable indicating whether or not a child has received vitamin A supplementation.

\section{Covariates}

The covariates included in the analysis are children's age in months (12-23, 24-35), sex of the child (male, female), birth order (1, 2-3, 4-5, 6+), breastfeeding status (not breastfeeding, breastfeeding), type of residence (urban, rural), mother's education (no education, primary, secondary complete, high school and above) and wealth index. The NFHS-3 wealth index is based on the following 20 assets and housing characteristics: Household electrification (electricity, kerosene, gas or oil, other source of lighting), drinking water source (pipe, hand pump, well in residence/ yard/plot, public tap, hand pump, well, other water source), type of toilet facility (own flush toilet, public or shared flush toilet 
or own pit toilet, shared or public pit toilet, no facility), type of house (pucca, semi pucca, kachha), cooking fuel (electricity, liquefied natural gas, or biogas, coal, charcoal, or kerosene, other fuel), house ownership (yes, no), number of household members per sleeping room and ownership of a car, tractor, moped/scooter/motorcycle, telephone, refrigerator, or color television, bicycle, electric fan, radio/transistor, sewing machine, black-and-white television, water pump, bullock cart or thresher, mattress, pressure cooker, chair, cot/bed, table or clock/watch.

An index for the social and economic development status of the states has been calculated by arranging the States of India according to percentage of women with more than primary education (female education is an important indicator for State's social status) and the percentage of households falling in the fourth and highest category of the wealth index. The variable is called "State's social and economic development status," and the composite score from the two indicators ranged between 23.5 and 72.5 . Scores ranged from 23.5 to 29.9 for states with low social and economic development status (the six states that fall in this category are Chhattisgarh, Bihar, Jharkhand, Madhya Pradesh, Orissa and Uttar Pradesh); 30.0 to 39.9 for states with medium-low social and economic development status (the eight States that fall in this category are Tripura, Arunachal Pradesh, Rajasthan, West Bengal, Assam, Meghalaya, Andhra Pradesh and Nagaland); 40.0 to 51.0 for states with medium-high social and economic development status (the eight States that fall in this category are Karnataka, Tamil Nadu, Manipur, Jammu and Kashmir, Uttarakhand, Haryana, Sikkim and Gujarat); and 52.0 to 72.5 for states with high social and economic development status (the seven states that fall in this category are Maharashtra, Himachal Pradesh, Punjab, Mizoram, Goa, Kerala and Delhi) $\cdot{ }^{[1]}$ (lowest, second, middle, fourth, highest), and the social and economic development status of the States of residence (high, medium-high, medium-low, low). ${ }^{[2]}$

\section{Statistical analysis}

Bivariate analysis was carried out to explore the differential among children receiving vitamin A by their mother's socioeconomic and demographic characteristics, followed by a Chi-square test to test the significance level. Association between children receiving vitamin A supplementation and their mother's socioeconomic characteristics and the State's social and economic development status was examined through unadjusted and adjusted binary logistic regression models. The dependent variable in this analysis is whether or not a child received vitamin A supplementation.

The results are presented in the form of odds ratios (ORs), with $95 \%$ confidence intervals ( $95 \%$ CIs). The estimation of confidence intervals takes into account design effects resulting from clustering at the level of the primary sampling unit. In the survey, certain States and certain categories of respondents were over sampled. Appropriate National and State weights were used to restore the representativeness of the sample. The analysis was conducted in Stata/SE 10. ${ }^{[13]}$

\section{Ethical considerations}

The survey got ethical clearance from the International Institute for Population Science's Ethical Review Board from where this survey was conducted. The analysis presented in this study is based on secondary analysis of existing survey data with all identifying information removed. The survey personnel obtained informed consent from each respondent before asking questions.

\section{RESULTS}

\section{State-wise differentials in vitamin A supplementation}

Table 1 gives the percentage of children aged 12-35 months who received vitamin A supplementation in the 6 months preceding the survey. Overall, one out of four children in India aged 12-35 months received vitamin A supplementation, which indicates poor coverage. Wide differentials have been noticed in vitamin A supplementation across the States, varying from less than $10 \%$ in states like Uttar Pradesh and Nagaland to more than $45 \%$ in states like Kerala, Mizoram and West Bengal.

\begin{tabular}{|c|c|c|c|}
\hline State & $\begin{array}{c}\text { Total } \\
\text { number of } \\
\text { children }\end{array}$ & $\begin{array}{l}\text { Number of } \\
\text { children } \\
\text { received } \\
\text { vitamin A }\end{array}$ & $\begin{array}{c}\text { Percentage } \\
\text { of children } \\
\text { received } \\
\text { vitamin A }\end{array}$ \\
\hline India & 20,802 & 5169 & 24.8 \\
\hline Uttar Pradesh & 2789 & 241 & 8.6 \\
\hline Nagaland & 922 & 82 & 8.9 \\
\hline Chhattisgarh & 579 & 83 & 14.3 \\
\hline Manipur & 768 & 117 & 15.2 \\
\hline Haryana & 464 & 74 & 15.9 \\
\hline Rajasthan & 743 & 122 & 16.4 \\
\hline Jammu and Kashmir & 484 & 83 & 17.1 \\
\hline Assam & 583 & 109 & 18.7 \\
\hline Arunachal Pradesh & 303 & 57 & 18.8 \\
\hline Madhya Pradesh & 1181 & 237 & 20.1 \\
\hline Delhi & 445 & 90 & 20.2 \\
\hline Uttaranchal & 449 & 92 & 20.5 \\
\hline Gujarat & 589 & 122 & 20.7 \\
\hline Punjab & 486 & 101 & 20.8 \\
\hline Meghalaya & 426 & 89 & 20.9 \\
\hline Karnataka & 825 & 188 & 22.8 \\
\hline Sikkim & 267 & 65 & 24.3 \\
\hline Jharkhand & 598 & 164 & 27.4 \\
\hline Andhra Pradesh & 852 & 247 & 29.0 \\
\hline Orissa & 679 & 200 & 29.5 \\
\hline Bihar & 915 & 298 & 32.6 \\
\hline Himachal Pradesh & 387 & 128 & 33.1 \\
\hline Maharashtra & 1272 & 479 & 37.7 \\
\hline Tripura & 250 & 103 & 41.2 \\
\hline Goa & 409 & 171 & 41.8 \\
\hline Tamil Nadu & 654 & 293 & 44.8 \\
\hline Kerala & 428 & 199 & 46.5 \\
\hline Mizoram & 344 & 160 & 46.5 \\
\hline West Bengal & 1009 & 472 & 46.8 \\
\hline
\end{tabular}

States of India are arranged according to ascending order of vitamin A supplementation, NFHS = National family health survey 


\section{Socioeconomic and demographic differentials in vitamin A supplementation coverage}

Table 2 shows the percentage distribution of children aged 12-35 months who received vitamin A supplementation in the 6 months preceding the survey by selected socioeconomic and demographic characteristics. About one-third of the children aged 12-23 months received vitamin A supplementation as compared with only one-fifth of the children aged 24-35 months. Girls and boys were equally likely to receive the supplementation. Vitamin A supplementation

\begin{tabular}{|c|c|c|c|c|c|}
\hline \multirow[t]{2}{*}{$\begin{array}{l}\text { Selected } \\
\text { characteristic }\end{array}$} & \multicolumn{2}{|c|}{$\begin{array}{c}\text { Did not receive } \\
\text { vitamin A }\end{array}$} & \multicolumn{2}{|c|}{$\begin{array}{l}\text { Received } \\
\text { vitamin A }\end{array}$} & \multirow{2}{*}{$\begin{array}{c}\mathrm{Chi}^{2} \\
P \text { value }\end{array}$} \\
\hline & Number & Percent & Number & Percent & \\
\hline $\begin{array}{l}\text { Child's age } \\
\text { (in months) }\end{array}$ & & & & & $<0.0001$ \\
\hline $12-23$ & 7253 & 46.4 & 3166 & 61.2 & \\
\hline $24-35$ & 8381 & 53.6 & 2003 & 38.8 & \\
\hline Child's sex & & & & & 0.143 \\
\hline Male & 8275 & 52.9 & 2781 & 53.8 & \\
\hline Female & 7358 & 47.1 & 2388 & 46.2 & \\
\hline Birth order & & & & & $<0.0001$ \\
\hline 1 & 4455 & 28.5 & 1881 & 36.4 & \\
\hline $2-3$ & 6844 & 43.8 & 2348 & 45.4 & \\
\hline $4-5$ & 2690 & 17.2 & 704 & 13.6 & \\
\hline $6+$ & 1644 & 10.5 & 235 & 4.5 & \\
\hline Breastfeeding status & & & & & $<0.0001$ \\
\hline Not breastfeeding & 6583 & 42.2 & 1724 & 33.4 & \\
\hline Breastfeeding & 9016 & 57.8 & 3439 & 66.6 & \\
\hline Residence & & & & & $<0.0001$ \\
\hline Urban & 3980 & 25.5 & 1456 & 28.2 & \\
\hline Rural & 11,653 & 74.5 & 3713 & 71.8 & \\
\hline Mother's education & & & & & $<0.0001$ \\
\hline No education & 8227 & 52.6 & 1791 & 34.6 & \\
\hline Primary complete & 2146 & 13.7 & 697 & 13.5 & \\
\hline $\begin{array}{l}\text { Secondary } \\
\text { complete }\end{array}$ & 4557 & 29.1 & 2292 & 44.3 & \\
\hline $\begin{array}{l}\text { High school and } \\
\text { above }\end{array}$ & 703 & 4.5 & 389 & 7.5 & \\
\hline Wealth Index & & & & & $<0.0001$ \\
\hline Lowest & 4150 & 26.5 & 1008 & 19.5 & \\
\hline Second & 3606 & 23.1 & 989 & 19.1 & \\
\hline Middle & 2982 & 19.1 & 1094 & 21.2 & \\
\hline Fourth & 2738 & 17.5 & 1077 & 20.8 & \\
\hline Highest & 2157 & 13.8 & 1001 & 19.4 & \\
\hline $\begin{array}{l}\text { State's social } \\
\text { and economic } \\
\text { development status }\end{array}$ & & & & & $<0.0001$ \\
\hline High & 1530 & 9.8 & 928 & 18.0 & \\
\hline Medium high & 2965 & 19.0 & 1006 & 19.5 & \\
\hline Medium low & 3244 & 20.8 & 1402 & 27.1 & \\
\hline Low & 7894 & 50.5 & 1833 & 35.5 & \\
\hline $\begin{array}{l}\text { Total number of } \\
\text { children }\end{array}$ & 15,633 & 100.0 & 5169 & 100.0 & \\
\hline
\end{tabular}

significantly decreased with the increasing birth order, but increased with mother's education and wealth status. Although the difference between urban and rural areas was small, the percentage was slightly higher in urban areas. Vitamin A supplementation improved as we moved from States with low socioeconomic development status to States with high socioeconomic development status.

\section{Characteristics of children who received vitamin A supplementation}

Table 3 shows selected socioeconomic and demographic characteristics of children who received vitamin A supplementation. A higher proportion of children received vitamin A supplementation whose mothers were educated to a level of high school and above, who belonged to households in the higher wealth quintile and who resided in States with a high socioeconomic development status. It is also evident from the table that more number of younger children (aged 12-23 months) received supplementation than older children. Also, more children in the first birth order received supplementation than did children higher in the birth order. However, no difference was observed regarding vitamin A supplementation according to a child's sex.

\section{Association between socioeconomic and demographic characteristics and vitamin $\mathrm{A}$ supplementation among children}

Table 4 presents the unadjusted and adjusted effect of socioeconomic and demographic characteristics on vitamin A supplementation among children aged 12-35 months by using logistic regression. Unadjusted logistic regression results show that mother's education, breastfeeding status of the child and household wealth status are positively associated but the childrens' age and birth order are inversely associated with vitamin A supplementation. However, in the adjusted model, the household wealth index has turned out to be an insignificant factor for vitamin A supplementation. Children whose mothers had high school and higher education were 2.4-times more likely (OR: 2.40; 95\% CI: 2.04-2.83; $P<0.0001$ ) to receive vitamin A supplementation than children whose mothers were illiterate. Even children whose mothers had at least primary school education were almost one and a half times more (OR: 1.35; 95\% CI: 1.21-1.50; $P<0.0001)$ likely to receive vitamin A supplementation than those with illiterate mothers. Interestingly, the rural areas that showed less likelihood of the children receiving vitamin A supplementation (OR: 0.87; 95\% CI: 0.81-0.93; $P<0.0001$ ) in the unadjusted model showed a higher likelihood of the children receiving vitamin $\mathrm{A}$ supplementation in the adjusted model (OR: 1.20; 95\% CI: 1.10-1.30; $P<0.0001)$. Children born in the higher birth order (6+) (OR: 0.54; 95\% CI: 0.46-0.63; $P<0.0001)$ and residing in States with low social and economic development status (OR: 0.51; 95\% CI: 0.46-0.57; $P<0.0001)$ were half as likely to receive vitamin A supplementation than children born in the lower birth order of birth and residing in States with high social and economic development status.

\section{DISCUSSION}

This study demonstrated the association between socioeconomic and demographic factors, the State's social and economic development status and vitamin A supplementation among preschool children 


\begin{tabular}{|c|c|c|c|}
\hline $\begin{array}{l}\text { Selected } \\
\text { characteristic }\end{array}$ & $\begin{array}{l}\text { Number of } \\
\text { children who } \\
\text { received } \\
\text { vitamin a } \\
\text { supplementation }\end{array}$ & $\begin{array}{l}\text { Percent } \\
(95 \% \mathrm{Cl})\end{array}$ & $\begin{array}{c}\text { Total } \\
\text { number of } \\
\text { children }\end{array}$ \\
\hline \multicolumn{4}{|l|}{$\begin{array}{l}\text { Child's age } \\
\text { (in months) }\end{array}$} \\
\hline $12-23$ & 3166 & $30.4(29.5-31.3)$ & 10,419 \\
\hline $24-35$ & 2003 & $19.3(18.5-20.1)$ & 10,384 \\
\hline \multicolumn{4}{|l|}{ Child's sex } \\
\hline Male & 2781 & $25.2(24.3-26.0)$ & 11,056 \\
\hline Female & 2388 & $24.5(23.7-25.4)$ & 9746 \\
\hline \multicolumn{4}{|l|}{ Birth order } \\
\hline 1 & 1881 & $29.7(28.6-30.8)$ & 6336 \\
\hline $2-3$ & 2348 & $25.5(24.7-26.4)$ & 9192 \\
\hline $4-5$ & 704 & $20.7(19.4-22.1)$ & 3394 \\
\hline $6+$ & 235 & $12.5(11.0-14.1)$ & 1879 \\
\hline \multicolumn{4}{|l|}{$\begin{array}{l}\text { Breastfeeding } \\
\text { status }\end{array}$} \\
\hline $\begin{array}{l}\text { Not } \\
\text { breastfeeding }\end{array}$ & 1724 & $20.8(19.9-21.6)$ & 8307 \\
\hline Breastfeeding & 3439 & $27.6(26.8-28.4)$ & 12,455 \\
\hline \multicolumn{4}{|l|}{ Residence } \\
\hline Urban & 1456 & $26.8(25.6-28.0)$ & 5436 \\
\hline Rural & 3713 & $24.2(23.5-24.8)$ & 15,366 \\
\hline \multicolumn{4}{|l|}{$\begin{array}{l}\text { Mother's } \\
\text { education }\end{array}$} \\
\hline No education & 1791 & $17.9(17.1-18.6)$ & 10,018 \\
\hline $\begin{array}{l}\text { Primary } \\
\text { complete }\end{array}$ & 697 & $24.5(22.9-26.1)$ & 2843 \\
\hline $\begin{array}{l}\text { Secondary } \\
\text { complete }\end{array}$ & 2292 & $33.5(32.3-34.6)$ & 6849 \\
\hline $\begin{array}{l}\text { High school } \\
\text { and above }\end{array}$ & 389 & $35.6(32.8-38.5)$ & 1092 \\
\hline \multicolumn{4}{|l|}{ Wealth index } \\
\hline Lowest & 1008 & $19.5(18.5-20.7)$ & 5158 \\
\hline Second & 989 & $21.5(20.3-22.7)$ & 4595 \\
\hline Middle & 1094 & $26.8(25.5-28.2)$ & 4076 \\
\hline Fourth & 1077 & $28.2(26.8-29.7)$ & 3815 \\
\hline Highest & 1001 & $31.7(30.1-33.4)$ & 3158 \\
\hline \multicolumn{4}{|l|}{$\begin{array}{l}\text { State's social } \\
\text { and economic } \\
\text { development } \\
\text { status }\end{array}$} \\
\hline High & 928 & $37.8(35.8-39.7)$ & 2458 \\
\hline Medium high & 1006 & $25.3(24.0-26.7)$ & 3971 \\
\hline Medium low & 1402 & $30.2(28.9-31.5)$ & 4646 \\
\hline Low & 1833 & $18.8(18.1-19.6)$ & 9727 \\
\hline Total & 5169 & $24.8(24.3-25.4)$ & 20,802 \\
\hline
\end{tabular}

in India. This study found that the coverage of the vitamin A supplementation program in India is low and the State's social and economic development status and mother's education largely determines children receiving vitamin A supplementation.

We found evidence of socioeconomic inequalities and inequities and regional disparities in vitamin A supplementation in India, which several other studies in Asia and Africa have reported. ${ }^{[14-18]}$ Children whose mothers did not complete primary education and children living in poor households were less likely to receive supplementation. Higher vitamin A supplementation intake by rich households compared with middle-class/poor households in India showed an increased health inequity. However, we did not find any evidence of gender differentials in vitamin A supplementation coverage. Our results on the lack of evidence of gender inequality are similar to what was reported by Bishai and colleagues in Nepal. ${ }^{[19]}$

In India, one of the greatest challenges for the vitamin A supplementation program has been finding sustainable mechanisms to deliver it. In the late 1990s, vitamin A supplementation was linked with polio National Immunization Days (NIDs). Despite concerns about the phasing out of these campaigns, NIDs remained the most prominent strategy since 2004 , accounting for $26 \%$ of all delivery attempts. However, as polio eradication is gradually achieved, integration of vitamin A supplementation with NIDs becomes less of an option in some areas.

Vitamin A is an essential micronutrient for the immune system and plays an important role in maintaining the epithelial tissue in the body, besides performing a wide range of metabolic functions. It also performs important functions with respect to health promotion and disease prevention. ${ }^{[20]}$ Ensuring optimal vitamin A intake is, therefore, important. Supplementation has many potential advantages over fortification and dietary approaches for improving micronutrient intake. ${ }^{[21]}$

Vitamin A supplementation is the quickest way to improve the vitamin A status of children, and is the favored strategy in areas where the problem is widely prevalent. Improving the diet, even if it is difficult to achieve in the short term, is of paramount importance as it contributes to improvement in the overall nutritional status. Food fortification with vitamin A has proved to be an effective strategy for reducing VAD in some countries. A right mix of interventions tailored to the local circumstances is more likely to succeed in achieving the objective.

The current Indian government policy, reflected in the ICDS program, aimed at universal provision of nutritional supplements in physiological doses to children under 6 years of age, nutrition education to mothers and also mega-doses of vitamin A. A total of nine massive doses of synthetic vitamin A are given to children between the ages of 9 and 60 months. The ICDS program undoubtedly contributes toward treating and preventing clinical deficiencies in children. However, better management of existing programs has been recommended by international bodies such as UNICEF to help tackle VAD in India. It has been recommended that every child under 5 years should receive at least two doses in a year.

The achievement of optimal nutritional status calls for an adequate intake of nutrients (macronutrients, micronutrients and phytonutrients), all of which can be derived from a balanced diet based on a judicious combination of available, traditional foods. ${ }^{[20]}$ However, the near-exclusive emphasis on vitamin A should not obscure the need for a sensible food-based approach toward ensuring the well being of populations. There is considerable information today on the inter-relationships among micronutrients. Exclusively pushing the intake of a single micronutrient in a population suffering from multiple micronutrient deficiencies could lead to undesirable results. ${ }^{[2]}$ 


\begin{tabular}{|c|c|c|c|c|}
\hline Selected characteristic & Unadjusted OR (95\% Cl) & $P$ value & Adjusted model OR $(95 \% \mathrm{Cl})$ & $P$ value \\
\hline \multicolumn{5}{|l|}{ Child's age (in months) } \\
\hline $12-23^{R}$ & 1.00 (reference) & & 1.00 (reference) & \\
\hline $24-35$ & $0.55(0.51-0.58)$ & $<0.0001$ & $0.61(0.57-0.65)$ & $<0.0001$ \\
\hline \multicolumn{5}{|l|}{ Child's sex } \\
\hline Male ${ }^{R}$ & 1.00 (reference) & & 1.00 (reference) & \\
\hline Female & $0.97(0.91-1.03)$ & 0.274 & $0.99(0.93-1.06)$ & 0.822 \\
\hline \multicolumn{5}{|l|}{ Birth order } \\
\hline $1^{\mathrm{R}}$ & 1.00 (reference) & & 1.00 (reference) & \\
\hline $2-3$ & $0.81(0.76-0.87)$ & $<0.0001$ & $0.89(0.83-0.96)$ & 0.003 \\
\hline $4-5$ & $0.62(0.56-0.68)$ & $<0.0001$ & $0.89(0.80-0.99)$ & 0.036 \\
\hline $6+$ & $0.34(0.29-0.39)$ & $<0.0001$ & $0.54(0.46-0.63)$ & $<0.0001$ \\
\hline \multicolumn{5}{|l|}{ Breastfeeding status } \\
\hline Not breastfeeding ${ }^{R}$ & 1.00 (reference) & & 1.00 (reference) & \\
\hline Breastfeeding & $1.46(1.36-1.56)$ & $<0.0001$ & $1.39(1.29-1.50)$ & $<0.0001$ \\
\hline \multicolumn{5}{|l|}{ Residence } \\
\hline Urban $^{R}$ & 1.00 (reference) & & 1.00 (reference) & \\
\hline Rural & $0.87(0.81-0.93)$ & $<0.0001$ & $1.20(1.10-1.30)$ & $<0.0001$ \\
\hline \multicolumn{5}{|l|}{ Mother's education } \\
\hline No education ${ }^{R}$ & 1.00 (reference) & & 1.00 (reference) & \\
\hline Primary complete & $1.49(1.35-1.65)$ & $<0.0001$ & $1.35(1.21-1.50)$ & $<0.0001$ \\
\hline Secondary complete & $2.31(2.15-2.48)$ & $<0.0001$ & $2.02(1.85-2.22)$ & $<0.0001$ \\
\hline High school and above & $2.54(2.22-2.91)$ & $<0.0001$ & $2.40(2.04-2.83)$ & $<0.0001$ \\
\hline \multicolumn{5}{|l|}{ Wealth index } \\
\hline Lowest $^{R}$ & 1.00 (reference) & & 1.00 (reference) & \\
\hline Second & $1.13(1.02-1.25)$ & 0.015 & $0.93(0.84-1.03)$ & 0.160 \\
\hline Middle & $1.51(1.37-1.67)$ & $<0.0001$ & $1.08(0.97-1.20)$ & 0.153 \\
\hline Fourth & $1.62(1.47-1.79)$ & $<0.0001$ & $1.01(0.89-1.13)$ & 0.930 \\
\hline Highest & $1.91(1.73-2.12)$ & $<0.0001$ & $0.99(0.85-1.14)$ & 0.838 \\
\hline \multicolumn{5}{|c|}{ State's social and economic development status } \\
\hline $\mathrm{High}^{R}$ & 1.00 (reference) & & 1.00 (reference) & \\
\hline Medium high & $1.86(1.72-2.02)$ & $<0.0001$ & $0.64(0.57-0.71)$ & $<0.0001$ \\
\hline Medium low & $1.46(1.34-1.60)$ & $<0.0001$ & $0.87(0.78-0.97)$ & 0.014 \\
\hline Low & $2.61(2.37-2.87)$ & $<0.0001$ & $0.51(0.46-0.57)$ & $<0.0001$ \\
\hline
\end{tabular}

${ }^{R}$ reference category

\section{Strengths and limitations of the study}

The strength of our study includes the large nationally representative data with wide geographical, regional and state-wise variations. However, this study had potential limitations. From a methodological point of view, the weakness of the study is that it is based on a cross-sectional design. The inherent problem of a cross-sectional design is that the outcome (vitamin A supplementation status) and the exposure (in this case, socioeconomic characteristics and a State's social and economic development status) are collected simultaneously, thereby preventing conclusions regarding causality. Second, we depended largely on the mothers' accounts of the vitamin A supplementation status of their children. The field investigators also checked the child's vaccination card for information about vitamin A supplementation, but this had limited use as the vaccination card did not necessarily have the information on vitamin A doses and also the health care workers in India are trained not to record the vitamin A dose on the children's vaccination cards. Third, the survey was designed primarily to collect data on population, health and nutrition for men aged 15-54 years and women aged 15-49 years in India and states. The information on vitamin A supplementation (as recommended by the UNICEF and $\mathrm{WHO}^{[23]}$ ) in the survey was covered as part of one of the various interventions for children under five in India.

\section{CONCLUSION}

The national vitamin A supplementation program in India did not reach a majority of preschool children in 2005 . The program was not uniformly successful in reaching the most vulnerable children. Greater maternal formal education, higher household wealth status and high social development status of their State of residence appears to be an important determinant for receipt of vitamin A supplementation by preschool children in India. Approaches targeting vulnerable households and states with low social and economic development status may be more promising. In order to increase the overall vitamin A supplementation coverage and reduce state-wise disparities, it is suggested that mass vitamin 
A supplementation programs be organized on a regional level, prioritizing the states with low social and economic development.

\section{ACKNOWLEDGEMENTS}

An earlier version of the paper was presented at the oral session of the XIII Annual Scientific Conference of the ICDDR, B, Dhaka, Bangladesh, 14-17 March 2011. The support of Macro International (Calverton, Maryland, USA) and International Institute for Population Sciences (Mumbai, India) for providing access to the 2005-2006 Indian National Family Health Survey 3 data is greatly acknowledged. We are also grateful to the anonymous referee for his/her valuable comments and suggestions.

\section{REFERENCES}

1. Black RE, Morris SS, Bryce J. Where and why are 10 million children dying every year? Lancet 2003;361:2226-34.

2. Claeson M, Gillespie D, Mshinda H, Troedsson H, Victora CG. Bellagio Study Group on Child Survival. Knowledge into action for child survival. Lancet 2003;362:323-7.

3. Jones G, Steketee RW, Black RE, Bhutta ZA, Morris SS. Bellagio Child Survival Study Group. How Many Child Deaths can we Prevent this Year? Lancet 2003;362:65-71.

4. Edejer TT, Aikins M, Black R, Wolfson L, Hutubessy R, Evans DB. Cost Effectiveness Analysis of Strategies for Child Health in Developing Countries. Br Med J 2005;331:1177-82.

5. World Bank. World Development Report: Investing in health. New York: Oxford University Press; 1993. p. 61-76.

6. Sommer A, Davidson FR. 25 Years of progress in controlling vitamin A deficiency: Looking to the future. Proceedings and abstracts of the $X X$ International Vitamin A Consultative Group Meeting. Hanoi, Vietnam, 12-15 February 2001. J Nutr 2002;132:2843S-990.

7. West KP Jr. Extent of Vitamin A Deficiency among Preschool Children and Women of Reproductive Age. J Nutr 2002;132:2857S-66.

8. World Health Organization. The World Health Report 2002: Reducing risks, promoting healthy life. Geneva: WHO; 2002. p. 55.

9. Beaton $\mathrm{GH}$, Martorell R, Aronson KJ, Edmonston B, McCabe G, Ross AC, et al. Effectiveness of vitamin A supplementation in the control of young child morbidity and mortality in developing countries. UN, ACC/SCN State-of-the-art Series, Nutrition policy Discussion Paper No. 13, 1993.

10. Reddy V. Vitamin A Programme in India - Why the Controversy? An excerpt from Sight and Life Newsletter 2002; Special Issue: 55. Available from: http://www.ifm.net/industry/vitamin_a_program.htm [Last accessed on 2012 Jun 6].

11. Kapil U. Do We Need Campaign Approach of Vitamin A Administration in Non Vitamin A Deficient Areas? Indian J Pediatr 2001;68:39-40.

12. International Institute for Population Sciences and Macro International. National Family Health Survey (NFHS-3) 2005-06. Vol. 1. Mumbai: IIPS; 2007. p. 292.

13. Stata Corp. Stata Statistical Software: Release 8.0. In College Station, Texas: Stata Corporation; 2003.

14. Choi $Y$, Bishai D, Hill K. Socioeconomic differentials in supplementation of vitamin A: Evidence from the Philippines. J Health Popul Nutr 2005;23:156-64.

15. Semba RD, de Pee S, Sun K, Bloem MW, Raju VK. Coverage of the national vitamin A supplementation program in Ethiopia. J Trop Pediatr 2008;54:141-4.

16. Grover DS, Pee S, Sun K, Raju VK, Bloem MW, Semba RD. Vitamin A supplementation in Cambodia: Program coverage and association with greater maternal formal education. Asia Pac J Clin Nutr 2008;17:446-50.

17. Semba RD, de Pee S, Sun K, Akhter N, Bloem MW, Raju VK. Coverage of Vitamin A Capsule Programme in Bangladesh and Risk Factors Associated with Non-receipt of Vitamin A. J Health Popul Nutr 2010;28:143-8.

18. Bendech MA, Cusack G, Konaté F, Touré A, Ba M, Baker SK. National vitamin A supplementation coverage survey among 6-59 months old children in Guinea (West Africa). J Trop Pediatr 2007;53:190-6.

19. Bishai D, Samir Kumar KC, Waters H, Koenig M, Katz J, Khatry SK, et al. The impact of vitamin A supplementation on mortality inequalities among children in Nepal. Health Policy Plan 2005;20:60-6.

20. Gopalan C. Massive dose vitamin A prophylaxis should now be scrapped. World Nutr 2010;1:79-85.

21. Shrimpton R, Schultink W. Can supplements help meet the micronutrient needs of the developing world? Proc Nutr Soc 2002;10:223-9.

22. Kapil U. Time to stop giving indiscriminate massive doses of synthetic vitamin A to Indian children. Public Health Nutr 2009;12:285-6.

23. Victora CG, Bryce J, Lambrechts T. The IMCl Impact Model and Community Based Indicators for the Multi-Country Evaluation of $\mathrm{IMCl}$ Effectiveness. Available from: http://www.who.int/imci-mce/Publications/ im_p5.pdf, webcite; Available from: http://www who int/imci-mce/ Publications/ [Last accessed on 1998].

How to cite this article: Agrawal S, Agrawal PK. Vitamin A supplementation among children in India: Does their socioeconomic status and the economic and social development status of their state of residence make a difference?. Int J Med Public Health 2013;3:48-54.

Source of Support: SA is supported by a Wellcome Trust Strategic Award Grant No Z/041825, Conflict of Interest: None declared. 